\title{
Correction to: Pyroptosis: a new paradigm of cell death for fighting against cancer
}

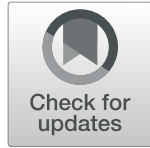

Yixin Tan ${ }^{1,2,3,4}$, Quanzhu Chen ${ }^{1,2,3}$, Xiaoling Li $i^{1,2,3}$, Zhaoyang Zeng ${ }^{1,2,3}$, Wei Xiong ${ }^{1,2,3}$, Guiyuan Li $i^{1,2,3}$, Xiayu Li ${ }^{3}$, Jianbo Yang ${ }^{5}$, Bo Xiang ${ }^{1,2,3^{*}}$ (i) and Mei Yi ${ }^{1,2,6^{*}}$

Correction to: J Exp Clin Cancer Res 40, 153 (2021)
https://doi.org/10.1186/s13046-021-01959-x

Following publication of the original article [1], the authors identified some minor errors in the Affiliation $\# 1$ and Affiliation \#2 details. The correct details are as follows:

1 Hunan Key Laboratory of Cancer Metabolism, Hunan Cancer Hospital and the Affiliated Cancer Hospital of Xiangya School of Medicine, Central South University, Tongzipo Road, Changsha, 410013, Hunan, University of Minnesota, Minneapolis, MN 55455, USA. ${ }^{6}$ Department of Dermatology, Xiangya Hospital, The Central South University, Changsha 410008, Hunan, China.

Published online: 22 September 2021

Reference

1. Tan Y, Chen Q, Li X, et al. Pyroptosis: a new paradigm of cell death for fighting against cancer. J Exp Clin Cancer Res. 2021;40:153 https://doi.org/1 0.1186/s13046-021-01959-x. China.

2 NHC Key Laboratory of Carcinogenesis, The Key Laboratory of Carcinogenesis and Cancer Invasion of the Chinese Ministry of Education, Cancer Research Institute and School of Basic Medical Sciences, Central South University, Changsha 410078, Hunan, China.

The correction does not have any effect on the results or conclusions of the paper. The original article has been corrected.

\begin{abstract}
Author details
${ }^{1}$ Hunan Key Laboratory of Cancer Metabolism, Hunan Cancer Hospital and the Affiliated Cancer Hospital of Xiangya School of Medicine, Central South University, Tongzipo Road, Changsha 410013, Hunan, China. ${ }^{2} \mathrm{NHC}$ Key Laboratory of Carcinogenesis, The Key Laboratory of Carcinogenesis and Cancer Invasion of the Chinese Ministry of Education, Cancer Research Institute and School of Basic Medical Sciences, Central South University, Changsha 410078, Hunan, China. ${ }^{3}$ Hunan Key Laboratory of Nonresolving Inflammation and Cancer, The Third Xiangya Hospital, Central South University, Changsha 410013, Hunan, China. ${ }^{4}$ Department of Dermatology, The Second Xiangya Hospital, The Central South University, Changsha 410011, Hunan, China. ${ }^{5}$ Department of Laboratory Medicine and Pathology,
\end{abstract}

The original article can be found online at https://doi.org/10.1186/s13046021-01959-x.

*Correspondence: xiangbolin@csu.edu.cn; yi_mei@csu.edu.cn

${ }^{1}$ Hunan Key Laboratory of Cancer Metabolism, Hunan Cancer Hospital and the Affiliated Cancer Hospital of Xiangya School of Medicine, Central South University, Tongzipo Road, Changsha 410013, Hunan, China

Full list of author information is available at the end of the article

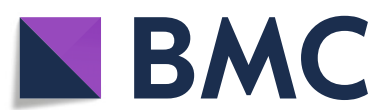

(c) The Author(s). 2021 Open Access This article is licensed under a Creative Commons Attribution 4.0 International License, which permits use, sharing, adaptation, distribution and reproduction in any medium or format, as long as you give appropriate credit to the original author(s) and the source, provide a link to the Creative Commons licence, and indicate if changes were made. The images or other third party material in this article are included in the article's Creative Commons licence, unless indicated otherwise in a credit line to the material. If material is not included in the article's Creative Commons licence and your intended use is not permitted by statutory regulation or exceeds the permitted use, you will need to obtain permission directly from the copyright holder. To view a copy of this licence, visit http://creativecommons.org/licenses/by/4.0/ The Creative Commons Public Domain Dedication waiver (http://creativecommons.org/publicdomain/zero/1.0/) applies to the data made available in this article, unless otherwise stated in a credit line to the data. 